\title{
Development and validation of an abbreviated version of the Trust in Oncologist Scale— the Trust in Oncologist Scale-short form (TiOS-SF)
}

\author{
Marij A. Hillen $^{1}$ - Rosa-May Postma ${ }^{1}$ - Mathilde G. E. Verdam ${ }^{1,2} \cdot$ Ellen M. A. Smets ${ }^{1}$
}

Received: 11 May 2016/Accepted: 26 October 2016/Published online: 10 November 2016

(C) The Author(s) 2016. This article is published with open access at Springerlink.com

\begin{abstract}
Purpose The original 18-item, four-dimensional Trust in Oncologist Scale assesses cancer patients' trust in their oncologist. The current aim was to develop and validate a short form version of the scale to enable more efficient assessment of cancer patients' trust.

Methods Existing validation data of the full-length Trust in Oncologist Scale were used to create a short form of the Trust in Oncologist Scale. The resulting short form was validated in a new sample of cancer patients $(n=92)$. Sociodemographics, medical characteristics, trust in the oncologist, satisfaction with communication, trust in healthcare, willingness to recommend the oncologist to others and to contact the oncologist in case of questions were assessed. Internal consistency, reliability, convergent and structural validity were tested.

Results The five-item Trust in Oncologist Scale Short Form was created by selecting the statistically best performing item from each dimension of the original scale, to ensure content validity. Mean trust in the oncologist was high in the validation sample (response rate $86 \%, M=4.30, S D=0.98)$. Exploratory factor
\end{abstract}

Marij A. Hillen

M.A.Hillen@amc.uva.nl

1 Department of Medical Psychology-Academic Medical Center, University of Amsterdam, P.O. Box 22700, 1100

DD Amsterdam, The Netherlands

2 Research Institute of Child Development and Education, University of Amsterdam, Amsterdam, The Netherlands analyses supported one-dimensionality of the short form. Internal consistency was high, and temporal stability was moderate. Initial convergent validity was suggested by moderate correlations between trust scores with associated constructs.

Conclusions The Trust in Oncologist Scale Short Form appears to efficiently, reliably and validly measures cancer patients' trust in their oncologist. It may be used in research and as a quality indicator in clinical practice. More thorough validation of the scale is recommended to confirm this initial evidence of its validity.

Keywords Trust · Physician-patient relations . Communication $\cdot$ Psychometrics $\cdot$ Oncology

\section{Introduction}

Patients need to trust their health care professionals when confronted with illness, even when no previous relationship with their provider exists [1]. Patients' trust has been defined as the optimistic acceptance of a vulnerable situation in which the patients believe the physician cares for his or her best interests [2]. Especially when facing a severe disease like cancer, trust is a prerequisite for an optimal treatment relation, and patients may even feel they literally have to trust their oncologist with their lives [3, 4].

Optimal trust between patients and their oncologist positively affects patients' treatment experience and outcomes. It leads to improved information exchange, better adherence to the physician's recommendations, reduced fear and less second opinion seeking [2, 4-8]. At present, little empirical evidence is available about how 
cancer patients' trust is constructed or how it may evolve [8]. Because of its crucial importance to oncology practice, we need to obtain a thorough understanding of the nature, predictors and consequences of trust between cancer patients and their oncologists. Such evidence may be used to maintain and improve patients' trust, for example, by means of physician training [9]. Thorough research on cancer patients' trust, however, first requires a proper measurement instrument.

Previous measures to assess trust have been diseasegeneric and developed in primary care mainly [4, 10]. These scales might not adequately capture cancer patients' trust, which has been found to be distinctly constructed [3]. Therefore, an oncology-specific measure to assess cancer patients' trust, the Trust in Oncologist Scale (TiOS), has been developed. The TiOS was developed from a theoretical framework and based on qualitative research. It was previously validated in both Dutch and English [11, 12].

The TiOS consists of 18 items that measure four theoretically based dimensions of trust, i.e. Competence: the oncologist's medical skills; Honesty: telling the truth and avoiding intentional falsehoods; Fidelity: the oncologist's acting in the patient's best interests; and Caring: the oncologist's involvement, sympathy and devotion of attention to the patient. Additionally, two global items are included as overall trust assessments. These dimensions were initially based on the dimensions of Hall et al.'s Trust in Physician Scale [4], and modified after qualitative interviews with cancer patients [12].

In previous research assessing trust using the TiOS, there was evidence for both the aforementioned separate dimensions and for a single, over-arching component $[11,13]$. Considering there is precedence for a onedimensional scale, it may be possible to measure patients' trust in their oncologist more efficiently using a shorter version of the TiOS. Such an abbreviated version would be of particular interest for studies involving time constraints. A short scale would reduce patient and researcher burden. It could be applied more widely, for example, in research in which trust is not the primary focus, while retaining comparable reliability and validity. Moreover, it prevents the practice of researchers assembling short versions by selecting items at their own discretion, which could come at the cost of comparison and replication between studies.

Therefore, the aim of this study was to develop and validate a short version of the TiOS. To that end, we first created and validated a shortened scale based on two existing datasets. Next, the shortened scale was administered to a sample of cancer patients to further investigate internal consistency, reliability, as well as content, structural and convergent validity [14].

\section{Methods}

\section{Scale abbreviation}

\section{Sample and procedure}

The full-length 18-item Trust in Oncologist Scale asks patients to report their trust in their own oncologist. It consists of the four dimensions of trust: Fidelity, Competence, Honesty and Caring [6], and two global trust items. All items consist of a proposition in the second person singular, with a 5-point Likert answering scale ranging from 1 (strongly disagree) through 5 (strongly agree). Three items are negatively phrased. After recoding the negatively phrased items, a mean score is calculated by dividing the summed scores by 18 . Hence, the possible scores range from 1 to 5 , with 5 indicating the highest level of patients' trust in their oncologist. The scale was originally developed in Dutch, and tested for validity and reliability on a sample of Dutch cancer patients $(n=423)$ [12]. It was later translated to English and validated on a sample of Australian cancer patients $(n=175)$ [11].

\section{Analysis}

We aimed to create a one-dimensional five-item reliable and valid short form for the TiOS (the TiOS-SF), including one item from each dimension and one global item to ensure content validity. Data of both previous validation studies were used to ensure generalizability of results. Items were selected with high face validity (conceptually central to the dimension from which they were selected) and high statistical performance (high factor loadings, item-scale correlation, high correlations with individual items and maximal variability in responses). We aimed to select items for which results corresponded between the Dutch and Australian data sets. To test structural validity, the resulting five items were subjected to exploratory factor analysis (EFA) using SPSS 22 (IBM Ltd., Chicago, IL), with orthogonal rotation (varimax). An eigenvalue cutoff of $>1.0$ was used to indicate separate factors.

\section{Validation of TiOS-SF}

\section{Sample and procedure}

Adult cancer patients were recruited through PanelCom, a panel including patients currently or previously treated for cancer (see www.healthcommunication.nl/panelcom/). A random selection of 148 panel members was approached by e-mail and invited to fill in an online questionnaire within the next week, with the possibility to refuse participation. A reminder was sent to non-responders after 2 weeks. Approval for the study was obtained from a local, certified Medical 
Ethics Committee. Nevertheless, electronic informed consent was obtained for all participants. To perform test-retest correlations, consenting participants received a second questionnaire 4 weeks later. Consenting patients received the second questionnaire which contained only the five TiOS items.

\section{Measures}

In addition to the TiOS-SF, participants reported their sociodemographic characteristics, including gender, age, education level and country of origin. Self-reported disease characteristics were time since diagnosis, type of cancer and the number of previous consultations with the present oncologist. Four measures were assessed to establish discriminant validity. First, satisfaction should theoretically be correlated, although not perfectly, with trust scores, which was confirmed in previous psychometric research $[4,7,12]$. Satisfaction with the oncologist was measured with the 5-item Patient Satisfaction Questionnaire (PSQ), assessed on a 100-point visual analogue scale [8]. However, due to technical problems in the online questionnaire, data of four of the five PSQ items was lost. From experience, we know the first item is strongly correlated to the other items of PSQ $\left(r_{\mathrm{s}}>0.60\right)[5,6]$. For that reason, and to avoid data loss, the data of the first item instead of the average score on all five PSQ items was used to assess the relation between satisfaction and trust. Three additional items assessed, using 5-point Likert scales, (1) whether patients would recommend their oncologist to their close ones (completely disagree-completely agree), (2) whether patients would get into contact with their oncologist if something would bother them (certainly not-most certainly) and (3) patients' reported level of trust in the Dutch healthcare system (a lot of trust-very little trust). These measures were expected to correlate substantially, yet not perfectly with trust, based on previous findings $[4,12,15,16]$. The second questionnaire, aimed to establish temporal stability, included only the TiOSSF.

\section{Analysis}

Structural validity was determined using EFA with orthogonal rotation (varimax) to allow for other factor solutions than the presumed one-dimensionality. An eigenvalue cutoff of $>1.0$ was used to indicate separate factors. An indication for the scale's reliability was assessed by determining internal consistency (item-total and interitem correlations) and reliability (Cronbach's $\alpha$ and temporal stability) [14]. High internal consistency was expected and indicated by high item-total correlations $r>0.50$ and inter-item correlations of $r>0.50$ [17]. Reliability would be indicated by Cronbach's $\alpha>0.80$ [18] and by high temporal stability as indicated by 
Table 2 Sample characteristics for TiOS-SF validation

\begin{tabular}{|c|c|c|}
\hline \multirow[t]{3}{*}{ Age $(N=92)$} & $M$ & Range \\
\hline & 61 & $22-76$ \\
\hline & $N$ & Percent \\
\hline \multicolumn{3}{|l|}{ Gender $(n=92)$} \\
\hline Male & 45 & 49 \\
\hline Female & 47 & 51 \\
\hline \multicolumn{3}{|l|}{ Educational level $(n=92)$} \\
\hline None/primary school & 2 & 2 \\
\hline Secondary/lower level vocational school & 53 & 58 \\
\hline College/university & 34 & 37 \\
\hline Other & 3 & 3 \\
\hline \multicolumn{3}{|l|}{ Country of origin $(n=92)$} \\
\hline Netherlands & 85 & 92 \\
\hline Other & 7 & 8 \\
\hline \multicolumn{3}{|l|}{ Time since diagnosis $(n=89)$} \\
\hline$<1$ year & 2 & 2 \\
\hline $1-2$ years & 22 & 25 \\
\hline $3-4$ years & 29 & 33 \\
\hline $5-6$ years & 18 & 20 \\
\hline$>6$ years & 18 & 20 \\
\hline \multicolumn{3}{|l|}{ Type of cancer $\left(n=92^{\mathrm{a}}\right)$} \\
\hline Colon & 29 & 32 \\
\hline Breast & 17 & 19 \\
\hline Lung & 15 & 16 \\
\hline Genitourinary & 18 & 20 \\
\hline Lymph nodes/bone marrow/blood & 10 & 11 \\
\hline Other & 10 & 11 \\
\hline \multicolumn{3}{|l|}{$\begin{array}{l}\text { Number of consultations with present } \\
\text { oncologist }(n=92)\end{array}$} \\
\hline $1-10$ consultations & 27 & 29 \\
\hline 11-20 consultations & 29 & 32 \\
\hline $21-30$ consultations & 20 & 22 \\
\hline $31-40$ consultations & 5 & 5 \\
\hline$>40$ consultations & 9 & 10 \\
\hline Do not know & 2 & 2 \\
\hline
\end{tabular}

${ }^{\text {a }}$ Multiple responses allowed, so percentages do not add up to $100 \%$

correlations $>0.50$ between mean and individual item scores on the test and retest.

Convergent validity was assessed using non-parametric correlations between mean TiOS-SF scores with scores for satisfaction (PSQ item), recommending the oncologist, contacting the oncologist and trust in Dutch health care. Moderate, but not perfect correlations $\left(r_{\mathrm{s}} .20-0.50\right)$ were expected.

Finally, correlations between TiOS-SF scores and sample characteristics, i.e., age, gender, education, ethnicity and time since diagnosis were explored. All analyses were performed using SPSS 22 (SPSS Statistics version 22; IBM Ltd., Chicago, IL).

\section{Results}

\section{Scale abbreviation}

Factor loadings, item-total and inter-item correlations for the full-length TiOS have been reported elsewhere [11, 12]. To ensure content validity, Items 2 (Honesty), 6 (Competence), 14 (Caring), 15 (Fidelity) and 18 (Global) were selected based on their high factor loadings, itemtotal and inter-item correlations in both the Dutch and Australian data sets. Table 1 shows all selected items with corresponding means, standard deviations, skewness and item-total correlations. Mean trust in the oncologist was high in both the Dutch $(M=4.63, S D=0.51$, range $2.20-5.00$, skewness $=-1.79(S E=0.12))$ and the Australian $(4.55, S D=0.50$, range $2.80-5.00$, skewness $=$ $-0.93(S E=0.19))$ data sets.

EFA, performed in the Dutch and Australian validation sets of the five items, indicated a one-factor solution in both the Dutch (eigenvalue $=3.13$, explaining $63 \%$ of variance) and the Australian (eigenvalue $=3.35$, explaining $67 \%$ of variance) sample. Factor loadings were $>0.70$ for all five included items. Therefore, all were included in the TiOS-SF.

\section{Validation of TiOS-SF}

\section{Response rate}

Of the 148 patients invited to participate, 128 patients $(86 \%)$ responded, of whom 101 patients consented to participate (response rate $68 \%$ ). The most frequently mentioned reason for patients not to participate was that they did not have recent contact with their oncologist. Data of nine respondents were excluded because their data on the TiOS-SF were missing. In total, 92 questionnaires were included in analyses for the test and 61 for the retest (response rate retest 70\%).

\section{Sample and descriptive data}

Sample descriptives are presented in Table 2. Mean trust in the oncologist was $4.30(S D=0.98$, range $1-5$, skewness -1.95 $(S E=0.25))$. Skewness was below 2 for all individual items at test as well as retest. Nevertheless, substantial skewness did occur, indicating ceiling effects for trust scores.

\section{Factor analysis}

EFA on the TiOS-SF indicated a one-factor solution. This factor, with eigenvalue 4.09 , explained $82 \%$ of the total variance. Factor loadings are displayed in Table 3. 


\section{Reliability and internal consistency}

High reliability of the shortened TiOS was indicated by a Cronbach's $\alpha=0.94$. Initial test-retest correlations indicated poor temporal stability of the TiOS-SF $(r=.35$, $p<0.01$; ranging between $r=0.26$ (item 2) and $r=0.38$ (item 5) for individual items). However, visual inspection revealed three clear outliers, with almost reversed scores between test and retest. When removing these outliers, test-retest correlations went up to $r=0.67(p<0.001)$ overall, and $r=0.45$ (item 3 ) and $r=0.72$ (item 4). Item-total correlations ranged between $r=0.77$ and $r=0.94$ at test, and between $r=0.62$ and $r=0.89$ at retest (Table 3). Inter-item correlations ranged between $r_{s}=0.57$ and $r_{s}=0.77$.

\section{Validity}

Good convergent validity of the scale was suggested by moderate correlations of mean trust (TiOS-SF scores) with satisfaction as assessed with the single PSQ item $\left(M=82.68, S D=19.40, r_{\mathrm{s}}=0.524, p<0.01\right)$, and with trust in the Dutch healthcare system $(M=3.90$, $\left.S D=0.83 ; r_{\mathrm{s}}=0.289, p<0.05\right)$. Moreover, TiOS-SF correlated significantly with scores for recommending the oncologist $\left(M=4.38, S D=1.01, r_{\mathrm{s}}=0.430\right.$, $p<0.001)$ and contacting the oncologist $(M=4.37$, $\left.S D=0.97, r_{\mathrm{s}}=0.310, p<0.01\right)$.

\section{Correlations with sample characteristics}

All correlations between mean trust (TiOS-SF scores) and sample characteristics were non-significant $(p>0.05)$.

\section{Discussion and conclusion}

\section{Discussion}

In this study, the Trust in Oncologist Scale Short Form, a 5item version of the TiOS, was created and validated. Preliminary evidence indicates that the TiOS-SF may be an efficient, reliable and valid measure of cancer patients' trust. The five items represented all five dimensions included in the full length TiOS, i.e. Competence, Honesty, Fidelity, Caring and Global trust, thus ensuring content validity. Combined, these items form a coherent and one-dimensional scale, thus indicating good structural validity. Convergent validity was confirmed by moderate correlations of TiOS-SF with satisfaction, trust in the Dutch healthcare system, as well as willingness to recommend the oncologist to others and to contact the oncologist in case of questions. These correlations were largely comparable to earlier established correlations between these measures and the full-length TiOS [12]. Substantial inter-item and item-scale correlations indicated internal consistency. Reliability was suggested by high Cronbach's $\alpha$.

Temporal stability was unexpectedly moderate in this study, whereas it was strong in the validation of the original scale [12]. This finding may be attributed to a three outliers, for whom mean trust scores showed dramatic differences between the two time points. Due to a limited sample size, these outliers strongly influenced the overall test-retest correlations. It remains unclear whether these changes in scores reflect actual shifts in patients' trust or a misunderstanding. When removing these outliers, test-retest correlations were high, as expected.

Patient typically reported high levels of trust in their oncologists, as was expected based on earlier studies assessing cancer patients' trust $[12,19,20]$. Several authors have suggested that such high levels may reflect a strong need to trust,

Table 3 Characteristics of the items included in the TiOS-SF, in the current validation set $(n=92)$

\begin{tabular}{|c|c|c|c|c|c|c|c|c|c|}
\hline \multirow[t]{2}{*}{ Item } & \multirow[t]{2}{*}{ Content } & \multirow[t]{2}{*}{ Dimension } & \multirow{2}{*}{$\begin{array}{l}\text { Factor } \\
\text { loading } \\
\text { in EFA }\end{array}$} & \multicolumn{2}{|l|}{ Mean (SD) } & \multicolumn{2}{|c|}{ Skewness } & \multicolumn{2}{|c|}{$\begin{array}{l}\text { Item-total } \\
\text { correlation }\end{array}$} \\
\hline & & & & Test & Retest & Test & Retest & Test & Retest \\
\hline 1 & $\begin{array}{l}\text { Your doctor is totally honest in telling you about } \\
\text { all the different treatment options available for } \\
\text { your condition }\end{array}$ & Honesty & .85 & $4.32(1.11)$ & $4.37(0.83)$ & -1.84 & -1.31 & 0.768 & 0.706 \\
\hline 2 & $\begin{array}{l}\text { You think your doctor can handle any medical } \\
\text { situation, even a very serious one }\end{array}$ & Competence & .89 & $4.30(1.00)$ & $4.35(0.83)$ & -1.65 & -1.45 & 0.821 & 0.756 \\
\hline 3 & $\begin{array}{l}\text { Your doctor listens with care and concern to all the } \\
\text { problems you have }\end{array}$ & Caring & .90 & $4.27(1.15)$ & $4.35(0.86)$ & -1.80 & -1.22 & 0.847 & 0.748 \\
\hline 4 & $\begin{array}{l}\text { Your doctor will do whatever it takes to get you all } \\
\text { the care you need }\end{array}$ & Fidelity & .92 & $4.35(1.10)$ & $4.38(0.91)$ & -1.93 & -1.79 & 0.871 & 0.615 \\
\hline 5 & All in all, you have complete trust in your doctor & Global item & .96 & $4.28(1.07)$ & $4.38(0.92)$ & -1.74 & -1.73 & 0.935 & 0.887 \\
\hline
\end{tabular}

Five-point Likert scale: 1 = totally disagree, $2=$ disagree, $3=$ as much agree as disagree, $4=$ agree, $5=$ strongly agree 
resulting from patients' vulnerability and consequent dependence on their oncologist $[1,3,21]$.

\section{Limitations and future directions}

The present study provides initial evidence of reliability and validity. Future research is needed to corroborate these findings in larger and various samples of cancer patients. In particular, samples could be identified in which trust levels are lower, to avoid the ceiling effects present in the current study. Such samples might, for example, include patients seeking second opinions or patients who are currently not in a treatment relation with their oncologist. This would allow assessing whether the TiOS-SF can measure the full spectrum of trust levels, and elucidate possible correlations with patient characteristics that may presently have been obscured by ceiling effects. While promising, the present study presents only initial evidence for the reliability and validity of the TiOS-SF. Future research needs to more thoroughly establish convergent and divergent validity by correlating the TiOS-SF with other validated measures, including a full patient satisfaction scale. Finally, future research could further examine how trust is related to patients' socio-demographic and medical characteristics. In the present study, no such associations were established, whereas previous research suggests that a lower education level as well as higher age may be predictive of stronger trust in the oncologist [15, 16, 22-24]. Ceiling effects may explain why similar effects were not established in the present study.

\section{Conclusion and practice implications}

The TiOS-SF allows researchers to efficiently assess patients' levels of trust, without creating a high burden for patients resulting from lengthy surveys. It may therefore contribute to a better understanding of patients' trust. However, for more refined insights into various elements of patients' trust, the original 18 -item scale may be more suitable, as it allows a more thorough distinction between trust dimensions.

The TiOS-SF may be an efficient, reliable and valid measurement instrument to measure patients' trust in their oncologist. It may be used in research and clinical practice. In research, it can contribute to our understanding of cancer patients' trust, its predictors and consequences. In clinical practice, it may be used as a quality indicator.

\section{Compliance with ethical standards}

Conflict of interest The authors declare no conflicts of interest. The authors had full control over all primary data and will allow the journal to review the data if requested.

Funding This study was supported by the Dutch Cancer Society [grant number: UVA 2008-4015].
Open Access This article is distributed under the terms of the Creative Commons Attribution-NonCommercial 4.0 International License (http:// creativecommons.org/licenses/by-nc/4.0/), which permits any noncommercial use, distribution, and reproduction in any medium, provided you give appropriate credit to the original author(s) and the source, provide a link to the Creative Commons license, and indicate if changes were made.

\section{References}

1. Mechanic D, Meyer S (2000) Concepts of trust among patients with serious illness. Soc Sci Med 51(5):657-668

2. Hall MA, Dugan E, Zheng BY, Mishra AK (2001) Trust in physicians and medical institutions: what is it, can it be measured, and does it matter? Milbank Q 79(4):613-639

3. Hillen MA, Onderwater AT, Van Zwieten MCB, de Haes JC, Smets EM (2012) Disentangling cancer patients' trust in their oncologist: a qualitative study. Psychooncology 21(4):392-399

4. Hall MA, Zheng BY, Dugan E, Camacho F, Kidd KE, Mishra A, Balkrishnan R (2002) Measuring patients' trust in their primary care providers. Med Care Res Rev 59(3):293-318

5. Balkrishnan R, Dugan E, Camacho FT, Hall MA (2003) Trust and satisfaction with physicians, insurers, and the medical profession. Med Care 41(9): 1058-1064

6. Trachtenberg F, Dugan E, Hall MA (2005) How patients' trust relates to their involvement in medical care. J Fam Pract 54(4): 344-352

7. Thom DH, Ribisl KM, Stewart AL, Luke DA (1999) Further validation and reliability testing of the Trust in Physician Scale. Med Care 37(5):510-517

8. Hillen MA, de Haes HC, Smets EM (2011) Cancer patients' trust in their physician-a review. Psychooncology 20(3):227-241. doi:10.1002/pon.1745

9. Rolfe A, Cash-Gibson L, Car J, Sheikh A, McKinstry B (2014) Interventions for improving patients' trust in doctors and groups of doctors. Cochrane Database Syst Rev 3. doi:10.1002/14651858.CD004134.pub3

10. Anderson AA, Dedrick FD (1990) Development of the Trust in Physician Scale: a measure to assess interpersonal trust in patientphysician relationships. Psychol Rep 67(3f):1091-1100

11. Hillen MA, Butow PN, Tattersall MHN, Hruby G, Boyle FM, Vardy J, Kallimanis-King BL, de Haes JCJM, Smets EMA (2013) Validation of the English version of the Trust in Oncologist Scale (TiOS). Patient Educ Couns 91(1):25-28

12. Hillen MA, Koning CCE, Wilmink JW, Klinkenbijl JHG, Eddes EH, Kallimanis-King BL, de Haes JCJM, Smets EMA (2012) Assessing cancer patients' trust in their oncologist: development and validation of the Trust in Oncologist Scale (TiOS). Support Care Cancer 20(8):1787-1795. doi:10.1007/s00520-011-1276-8

13. Hillen MA, De Haes HCJM, Stalpers LJA, Klinkenbijl JHG, Eddes EH, Verdam MGE, Smets EMA (2014) How attachment style and locus of control influence patients' trust in their oncologist. J Psychosom Res 76(3):221-226

14. Mokkink LB, Terwee CB, Patrick DL, Alonso J, Stratford PW, Knol DL, Bouter LM, de Vet HC (2010) The COSMIN study reached international consensus on taxonomy, terminology, and definitions of measurement properties for health-related patient-reported outcomes. J Clin Epidemiol 63(7):737-745

15. Hillen MA, De Haes HCJM, Stalpers LJA, Klinkenbijl JHG, Eddes EH, Butow PN, van der Vloodt J, van Laarhoven HWM, Smets EMA (2014) How can communication by oncologists enhance patients' trust? An experimental study. Ann Oncol 25(4):896-901

16. Hillen MA, de Haes JCJM, van Tienhoven G, Bijker N, van Laarhoven HWM, Vermeulen DM, Smets EMA (2015) All eyes 
on the patient - the influence of oncologists' nonverbal communication on breast cancer patients' trust. Breast Cancer Res $\operatorname{Tr} 153(1)$ : 161-171. doi:10.1007/s10549-015-3486-0

17. Cohen J (1988) Statistical power analysis for the behavioral sciences. Lawrence Erlbaum Associates, Hillsdale, NJ

18. Nunnally JC (1978) An overview of psychological measurement. In: Clinical diagnosis of mental disorders. Springer, $p$ 97-146

19. Do YK, Carpenter WR, Spain P, Clark JA, Hamilton RJ, Galanko JA, Jackman A, Talcott JA, Godley PA (2010) Race, healthcare access and physician trust among prostate cancer patients. Cancer Cause Control 21:31-40

20. Kowalski C, Nitzsche A, Scheibler F, Steffen P, Albert U, Pfaff H (2009) Breast cancer patients' trust in physicians: the impact of patients' perception of physicians' communication behaviors and hospital organizational climate. Pat Educ Couns

21. Seetharamu N, Iqbal U, Weiner JS (2007) Determinants of trust in the patient-oncologist relationship. Palliat Support Care 5(4):405409

22. O'Malley AS, Sheppard VB, Schwartz M, Mandelblatt J (2004) The role of trust in use of preventive services among low-income African-American women. Prev Med 38(6):777-785

23. Kraetschmer N, Sharpe N, Urowitz S, Deber RB (2004) How does trust affect patient preferences for participation in decision making? Health Expect 7(4):317-326

24. Gordon HS, Street RL Jr, Sharf BF, Kelly PA, Souchek J (2006) Racial differences in trust and lung cancer patients' perceptions of physician communication. J Clin Oncol 24(6):904-909 